\title{
TECHNICALLY SOPISTICATED GOODS IN THE CONTEXT OF CONSUMER RIGHTS WHEN DEFECTS ARE DETECTED IN THE GOOD
}

\author{
Natalia A. Ablyatipova \\ Russian State University of Justice (Crimean Branch), Simferopol, Russian Federation \\ Anastasia A. Kravtsova \\ Russian State University of Justice (Crimean Branch), Simferopol, Russian Federation
}

Introduction: currently, retail sales contracts are widely used, under which technically sophisticated goods are transferred to the property, which form a special group of goods and have the specifics of the legal regulation. Meanwhile, there is no legal definition of a technically sophisticated good, and there are no regulatory criteria for this legal category. In this regard, the authors set the goal: to summarize the approaches developed by judicial practice on this issue, to identify what normative justification of technical sophistication is used when including goods in the List of technically sophisticated goods. Results: the importance of qualifying a product as technically sophisticated is investigated, the problems of qualifying goods as technically sophisticated are identified, and the reasons for determining the category of wireless devices equipped with a touch screen, two or more functions, and the absence of similar devices without a touch screen in the List of technically sophisticated products are established. Conclusions: based on the analysis of the legislation and the materials of judicial practice, the problems of applying the List of technically sophisticated goods and the ambiguity of the law enforcement are identified. Based on the results of the work, the authors have developed the practical proposals and recommendations for improving the legislation.

Key words: technically sophisticated goods, lack of goods, consumer rights, return of goods, purchase and sale, mobile device, telephone.

Citation. Ablyatipova N.A., Kravtsova A.A. Technically Sopisticated Goods in the Context of Consumer Rights when Defects are Detected in the Good. Legal Concept = Pravovaya paradigma, 2021, vol. 20, no. 1, pp. 19-26. (in Russian). DOI: https://doi.org/10.15688/lc.jvolsu.2021.1.3

\section{ТЕХНИЧЕСКИ СЛОЖНЫЕ ТОВАРЫ В КОНТЕКСТЕ ПРАВ ПОТРЕБИТЕЛЯ ПРИ ОБНАРУЖЕНИИ В ТОВАРЕ НЕДОСТАТКОВ}

\author{
Наталья Айдеровна Аблятипова \\ Российский государственный университет правосудия (Крымский филиал), \\ г. Симферополь, Российская Федерация
}

\begin{abstract}
Анастасия Алексеевна Кравцова
Российский государственный университет правосудия (Крымский филиал), г. Симферополь, Российская Федерация
\end{abstract} Введение: в настоящее время широко распространены договоры розничной купли-продажи, по кото-
рым в собственность передаются технически сложные товары, которые образуют особую группу товаров и
имеют специфику правового регулирования. Между тем отсутствуют легальное определение технически 
сложного товара, нормативные критерии данной правовой категории. В связи с этим авторами поставлена цель: обобщить выработанные судебной практикой подходы по данному вопросу, выявить, какое нормотворческое обоснование технической сложности применяется при включении товара в Перечень технически сложных товаров. Результаты: исследуется важность квалификации товара, как технически сложного, выявлены проблемы квалификации товаров, как технически сложных, и установлены причины определения в Перечне технически сложных товаров категории беспроводных устройств, оснащенных сенсорным экраном, двумя или более функциями и отсутствия в нем аналогичных устройств без сенсорного экрана. Выводы: на основе анализа законодательства и материалов судебной практики выделены проблемы применения перечня технически сложных товаров и неоднозначность правоприменения. По результатам работы авторами выведены практические предложения и рекомендации по совершенствованию законодательства.

Ключевые слова: технически сложные товары, недостаток товара, права потребителя, возврат товара, купля-продажа, мобильное устройство, телефонный аппарат.

Цитирование. Аблятипова Н. А., Кравцова А. А. Технически сложные товары в контексте прав потребителя при обнаружении в товаре недостатков // Legal Concept $=$ Правовая парадигма. -2021 . - Т. 20, № 1. C. 19-26. - DOI: https://doi.org/10.15688/lc.jvolsu.2021.1.3

\section{Введение}

В правовом регулировании отношений в области розничной купли-продажи одним из направлений поиска баланса интересов потребителей и предпринимателей выступает регулирование отношений по поводу реализации потребителем права на обмен (возврат) товара надлежащего качества и возможности реализации определенного законом объема правомочий в отношении товара, имеющего определенные недостатки качества, в том числе путем отказа от такого товара ненадлежащего качества. На сегодняшний день активно развивается экономическая сфера по производству и продаже технических товаров. Ряд технических товаров относятся к категории технически сложных товаров, что имеет значение для разрешения правоприменителем юридических вопросов, связанных договорными отношениями в сфере купли-продажи.

Следует отметить, что квалификация товара, как технически сложного имеет важное правовое значение для реализации прав потребителей при обнаружении обычного и существенного недостатка такого товара, определении требований и срока, в течение которого их может предъявить потребитель продавцу [1; 2], при этом стоит учитывать, что обоснование существенности недостатка может быть затруднительным. Проблема технически сложных товаров и реализации прав потребителей при обнаружении в таких товарах недостатков нашла свое отражение в исследованиях А.Ю. Прохорова [8], 3.А. Шутихиной [16].
Проблема отсутствия легального определения

правовой категории «технически сложный товар» и квалификация мобильных телефонов, смартфонов в качестве технически сложных товаров

Между тем, несмотря на важность надлежащей квалификации, правоприменителем товара в качестве технически сложного, в настоящее время отсутствуют легальное определение правовой категории «технически сложный товар» и нормативные критерии данной правовой категории.

Анализ пояснительных записок к некоторым Проектам Постановлений Правительства $[9 ; 10]$, которые направлены на внесение изменений в Постановление Правительства РФ от 10.11.2011 № 924 «Об утверждении перечня технически сложных товаров» (далее Перечень) [6], показывает, что при нормотворчестве обоснование технической сложности товара включает следующие аспекты. Первое, процесс производства таких товаров «отличается высокой технологичностью, учитывая работу специального конструкторского бюро на предприятиях, использование станков и токарных автоматов, применение разнообразных материалов и деталей, логистику, наличие необходимых высококвалифицированных кадров, проведение сертификации товаров». Кроме того, технически сложные товары, содержащиеся в п. 12 Перечня, охаракте- 
ризованы, как высокотехнологичные, электрические, многофункциональные, обладающие электронным блоком электронного управления, программируемые, такие, к которым при производстве применяются сложные инженерноконструкторские решения. Второе, указывается, что такие товары являются не менее технически сложными, чем те, которые уже наличествуют в Перечне, сопоставляются внутреннее устройство, конструкция и механизм работы с теми, которые обладают устройства, включенные в Перечень.

Непосредственно в Перечне технически сложных товаров [6] приведены наименования группы таких товаров, характеризующиеся высокой степенью обобщенности, либо содержится указание на отдельные свойства некоторых товаров данной категории. В силу отсутствия легального определения технически сложного товара правоприменитель устанавливает принадлежность спорного товара к определенной группе категории технически сложных товаров, либо наличие квалифицирующих свойств для признания товара технически сложным. Указанное влечет за собой существование в судебной практике нескольких оснований квалификации сенсорного смартфона, как технически сложного товара: п. 7 Перечня, в котором сконцентрирована группа товаров, составляющая «системные блоки, компьютеры стационарные и портативные, включая ноутбуки, и персональные электронные вычислительные машины» [6; 11]; п. 6 Перечня, в котором сгруппированы «оборудование навигации и беспроводной связи для бытового использования, в том числе спутниковой связи, имеющее сенсорный экран и обладающее двумя и более функциями» [6] (данное основание является более распространенным в практике судов) [12; 13; 14].

Кроме того, отсутствие легального определения технически сложного товара обуславливает парадоксальную зависимость квалификации в качестве технически сложного товара мобильного телефона, смартфона без сенсорного экрана (кнопочного устройства) от требований истца. Так, сроком продолжительностью по31.12.2020 г. к правоотношениям по обмену товара надлежащего качества применяется Перечень товаров надлежащего качества, не подлежащих обмену (утвержденный
Постановлением Правительства РФ от 19.01.1998 № 55), где наличествует такая категория товаров, как телефонные аппараты, как одна из составляющих группы технически сложных товаров бытового назначения [5]. С учетом позиции Роспортребнадзора РФ [15] кнопочный телефон определяется как технически сложный товар. (Следует отметить, что с 01.01.2021 г. вступил в действие соответствующий Перечень, утвержденный Постановлением Правительства РФ от 31.12.2020 № 2463 [7]. При этом перечисление элементов группы технически сложных товаров бытового назначения исключено).

Примечательно, что до 2021 г. сформировалась неоднозначная практика, когда мобильный телефон, смартфон без сенсорного экрана (кнопочное устройство) имеют недостаток и исходя из данного обстоятельства заявляется требование об отказе от такого товара, правоприменитель при использовании Перечня технически сложных товаров и осуществлении сопоставления с п. 6 данного Перечня, ввиду того, что, хотя устройство является беспроводным и имеет несколько функций, однако, не имеет сенсорного экрана делает вывод, что такой товар не является технически сложным [3].

Роспотребнадзором РФ разъяснено, что п. 11 Перечня непродовольственных товаров надлежащего качества не подлежащих обмену (утвержденного Постановлением Правительства РФ от 19.01.1998 № 55) и Перечень технически сложных товаров служат для реализации разных целей, а именно, для исполнения положений п. 1 ст. 25 и, соответственно, положений ст. 18 Закона РФ от 07.02.1992 № 2300-1 [4]. В этой связи закономерно, что положения п. 1 ст. 18 указанного закона неприменимы в отношении мобильного телефона, у которого отсутствует сенсорный экран [4]. Исходя из этого в правовом регулировании отношений в сфере розничной купли-продажи усматривается идея дифференциации по критерию отнесения товара к категории технически сложного, обусловленная поиском баланса между интересами потребителя и предпринимателя, соответственно. Установлены изъятия из общего правила реализации правомочий потребителя по двум направлениям: в отношении товара надлежащего 
качества и в отношении случая, когда продавец нарушил требования, предъявляемые к качеству товара; данные изъятия отражены в обособленных Перечнях. В таком разграничении видится следующая идея: существует категория технически сложных товаров, однако, в Перечень технически сложных товаров для целей ст. 18 Закона РФ от 07.02.1992 № 2300-1 включена лишь их часть.

Вместе с этим представляется, что при решении вопроса о возможности возврата мобильного телефона, смартфона стоит учитывать историю развития данной категории устройств. Изначально мобильные устройства использовались для осуществления телефонных разговоров и были без сенсорных экранов; с течением времени устройства усложнялись, дополнялись функциями фотографирования, мультимедийными функциями, мобильными играми (при этом они не были оснащены сенсорным экраном, имели небольшой объемом памяти и отличались сравнительной простой). Важным этапом в развитии техники стало появление сенсорных коммуникаторов, карманных персональных компьютеров, что предопределило последующие изменения ситуации на товарном рынке, где на сегодняшний день основным продуктом стали смартфоны, которые в основном обладают сенсорным экраном, а по своему функционалу существенно превосходят простые мобильные устройства, благодаря тому, что они оснащены определенными операционными системами, которыми чаще всего выступают IOS и Android. Можно предположить, что создание нового Перечня непродовольственных товаров надлежащего качества не подлежащих обмену, утвержденного Постановлением Правительства РФ от 31.12.2020 г. № 2463 (с учетом исключения конкретизации составляющих группы технически сложных товаров), не позволит разрешить обозначенную проблему, связанную с отказом от товара с недостатком и возвратом (обменом) товара надлежащего качества. Представляется, что целесообразным является несколько иное направление совершенствования правового регулирования. В частности, для определения возможности возвратить мобильный телефон, смартфон, отказаться от таковых, может быть положено разграничение именно по функцио- нальным свойствам устройств на простые мобильные телефоны, в отношении которых не будет ограничено право на возврат (обмен), отказ от товара, и смартфоны, коммуникаторы. В данном контексте стоит обратить внимание на проблему необходимости разграничения технических товаров и технически сложных товаров, поскольку данные категории не должны быть тождественными.

\section{Тенденция увеличения доли} технически сложных товаров

\section{в гражданском обороте и проблема} ограничения права потребителей на отказ от них

Можно предположить, что в связи с тем, что в товарном обороте становятся более распространенными беспроводные устройства, устройства, которые оснащаются сенсорным экраном, когда устройства все чаще выполняют две и более функции и такой набор свойств функций приобретает обычную практику в результате развития науки и техники; в правовом регулировании таких отношений, включая правительственное регулирование, и в судебной практике предстоит выработать подход будут ли такие устройства относиться к категории технически сложных товаров, в отношении которых должно быть ограничено право на отказ (для целей ст. 18 Закона РФ от 07.02.1992 № 2300-1), либо такие технические устройства можно свободно возвратить независимо от того, простой недостаток или существенный.

Например, в гражданском обороте широко представлены фитнес-браслеты, с учетом существующего правового регулирования, такие устройства правоприменителем или будут квалифицированы по п. 6 Перечня технически сложных товаров, либо нет, в зависимости от толкования категории «оборудование навигации и беспроводной связи». Представляется, что в таковом контексте имеется ввиду не любое устройство, которое взаимодействует с другим устройством удаленно без проводов, а только то, которое является само или устройством навигации, или средством связи для передачи информации другому лицу путем разговора и в таком случае фитнес-браслеты могут быть заменены при 
наличии простого недостатка. Такая логика связана с тем, что в 2011 г., когда был утвержден Правительством РФ указанный Перечень, наиболее распространенной категорией товаров, попадающих в группу товаров п. 6 Перечня были GPS-навигаторы и коммуникаторы. Кроме того, существуют модели фитнес-браслетов, не оснащенных сенсорным экраном, обладающие аналогичным с сенсорными устройствами функционалом.

\section{Выводы}

Таким образом, существует необходимость выработки легального определения технически сложного товара, критериев разграничения понятий «технически сложный товар» и «технический товар». Развитие науки и техники, изменения на товарном рынке обусловливают необходимость совершенствования регулирования отношений в области реализации права потребителя на отказ от товара, имеющего недостаток, в целях обеспечения баланса интересов потребителей и предпринимателей.

Решением в сложившейся ситуации с увеличением в гражданском обороте числа беспроводных устройств, устройств, которые оснащаются сенсорным экраном, когда устройства все чаще выполняют две и более функции, увеличением числа техники на товарном рынке, может стать законодательное и правительственное регулирование, которое, в результате анализа законодателем и Правительством товарного рынка, учета интересов потребителей и предпринимателей, пойдет по такому пути, что ряд технических товаров, включая часть товаров, которые на сегодняшний день относятся к категории технически сложных товаров будут выведены из-под ограничений в обмене и в отказе от товара при выявлении недостатка, не обладающего признаками существенного.

\section{СПИСОК ЛИТЕРАТУРЫ}

1. Гражданский кодекс Российской Федерации (часть вторая) от 26.01.1996 № 14-Ф3.- Электрон. текстовые дан. - Режим доступа: http:// www.consultant.ru (дата обращения: 10.01.2021). Загл. с экрана.
2. Закон РФ от 07.02.1992 № 2300-1 «О защите прав потребителей». - Электрон. текстовые дан. Режим доступа: http://www.consultant.ru (дата обращения: 10.01.2021). - Загл. с экрана.

3. Определение Буйского районного суда (Костромская область) от 10 июля 2013 г. по делу № 117/2013 г. // Судебные и нормативные акты РФ. Электрон. текстовые дан. - Режим доступа: http:// sudact.ru/regular/doc/wUeRc77k3h6W/ (дата обращения: 10.01.2021). - Загл. с экрана.

4. «Ответы на вопросы предпринимателей, поступившие в Управление Роспотребнадзора по г. Москве через сервис для сбора вопросов (обращений), замечаний и комментариев по докладам и при обсуждении докладов на публичных слушаниях 13 июля 2017 г. на публичных слушаниях правоприменительной практики Управления за II квартал 2017 года» (Управление Роспотребнадзора по г. Москве, 2017). - Электрон. текстовые дан. - Режим доступа: http://www.consultant.ru/cons/cgi/online.cgi? req $=$ doc $\&$ base $=$ MLAW $\& n=182763 \# 03934310176$ 828566 (дата обращения: 10.01.2021). - Загл. с экрана.

5. Постановление Правительства РФ от 19.01.1998 № 55 (ред. от 30.05.2018) «Об утверждении Правил продажи отдельных видов товаров, перечня товаров длительного пользования, на которые не распространяется требование покупателя о безвозмездном предоставлении ему на период ремонта или замены аналогичного товара, и перечня непродовольственных товаров надлежащего качества, не подлежащих возврату или обмену на аналогичный товар других размера, формы, габарита, фасона, расцветки или комплектации» // Собрание законодательства РФ. - 26.01.1998. - № 4. - Ст. 482.

6. Постановление Правительства РФ от 10.11.2011 № 924 (ред. от 27.03.2019) «Об утверждении перечня технически сложных товаров» // Собрание законодательства РФ. - 14.11.2011. - № 46. С. 6539.

7. Постановление Правительства РФ от 31.12.2020 № 2463 «Об угверждении Правил продажи товаров по договору розничной купли-продажи, перечня товаров длительного пользования, на которые не распространяется требование потребителя о безвозмездном предоставлении ему товара, обладающего этими же основными потребительскими свойствами, на период ремонта или замены такого товара, и перечня непродовольственных товаров надлежащего качества, не подлежащих обмену, а также о внесении изменений в некоторые акты Правительства Российской Федерации». Электрон. текстовые дан. - Режим доступа: http:// www.consultant.ru (дата обращения: 12.01.2021).Загл. с экрана.

8. Прохоров, А. Ю. Особенности реализации отдельных прав потребителей при обнаружении не- 
достатков приобретенных автотранспортных средств / А. Ю. Прохоров // Наука и образование: хозяйство и экономика; предпринимательство; право и управление. - 2015. - № 6 (61). - С. 93-96.

9. Проект Постановления Правительства РФ «О внесении изменений в Перечень технически сложных товаров» (по состоянию на 07.07.2016) (подготовлен Минпромторгом России) (Постановление подписано 17.09.2016 № 929). - Электрон. текстовые дан. - Режим доступа: http://www.consultant.ru (дата обращения: 10.01.2021). - Загл. с экрана.

10. Проект Постановления Правительства РФ «О внесении изменения в Перечень технически сложных товаров» (по состоянию на 05.10.2018) (подготовлен Минпромторгом России) (Постановление подписано 27.03.2019 № 327). - Электрон. текстовые дан. - Режим доступа: http://www.consultant.ru (дата обращения: 10.01.2021). - Загл. с экрана.

11. Решение Кировского районного суда г. Саратова № 2-4192/2018 2-4192/2018 М-4111/2018 M4111/2018 от 24 июля 2018 г. по делу № 2-4192/2018 // Судебные и нормативные акты РФ. - Электрон. текстовые дан. - Режим доступа: http://sudact.ru/ regular/doc/TuH5LbmBvMYw/ (дата обращения: 10.01.2021). - Загл. с экрана.

12. Решение Московского районного суда г. Чебоксары (Чувашская Республика) № 2-3944/2016 от 9 ноября 2016 г. по делу № 2-3944/2016 // Судебные и нормативные акты РФ. - Электрон. текстовые дан. Режим доступа: http://sudact.ru/regular/doc/ hhclUTd0GPQX/ (дата обращения: 10.01.2021). - Загл. с экрана.

13. Решение Назаровского городского суда (Красноярский край) № 2-1463/2015 2-20/2016 2-20/ 2016(2-1463/2015;) М-997/2015 М-997/2015 от 12 января 2016 г. по делу № 2-1463/2015 // Судебные и нормативные акты РФ. - Электрон. текстовые дан. - Режим доступа: http://sudact.ru/regular/doc/bc0zUCB7ewYv/ (дата обращения: 10.01.2021). - Загл. с экрана.

14. Решение Центрального районного суда г. Тольятти (Самарская область) № 2-3944/2018 2-3944/ 2018 M-3484/2018 M-3484/2018 от 24 сентября 2018 г. по делу № 2-3944/2018 // Судебные и нормативные акты РФ. - Электрон. текстовые дан. - Режим доступа: http://sudact.ru/regular/doc/IzV5cCS95bmX/ (дата обращения: 10.01.2021). - Загл. с экрана.

15. Решение Промышленного районного суда г. Ставрополя (Ставропольский край) № 2-9082/2015 2-9082/2015 М-9319/2015 М-9319/2015 от 17 декабря 2015 г. по делу № 2-9082/2015 // Судебные и нормативные акты РФ. - Электрон. текстовые дан. Режим доступа: http://sudact.ru/regular/doc/ Ub0HCgVK4uxw/ (дата обращения: 10.01.2021).Загл. с экрана.

16. Шутихина, 3. А. Понятие, правовая природа технически сложного товара как правовой кате- гории / 3. А. Шутихина // Аллея науки. - 2018. № 7 (23). - C. $821-825$.

\section{REFERENCES}

1. Grazhdanskij kodeks Rossijskoj Federacii (chast' vtoraja) ot 26.01.1996 № 14-FZ [The civil code of the Russian Federation (part two) Federal Law of January 26,1996 No. 14-FL]. URL: http:// www.consultant.ru (accessed 10 January 2021).

2. Zakon RF ot 07.02.1992 № 2300-1 «O zashhite prav potrebitelej» [The law of the Russian Federation February 7, 1992 No. 2300-1 'On consumer rights protection']. URL: http://www.consultant.ru (accessed 10 January 2021).

3. Opredeleniye Buyskogo rayonnogo suda (Kostromskaya oblast) ot 10 iyulya $2013 \mathrm{~g}$. po delu № 11-7/2013 g. [Ruling of the Buysky district court (Kostroma region) of July 10, 2013 in case No. 11-7/ 2013]. Sudebnyye i normativnyye akty RF. URL: http:/ /sudact.ru/regular/doc/wUeRc77k3h6W/ (accessed 10 January 2021).

4. «Otvety na voprosy predprinimateley. postupivshiye $v$ Upravleniye Rospotrebnadzora po g. Moskve cherez servis dlya sbora voprosov (obrashcheniy). zamechaniy i kommentariyev po dokladam i pri obsuzhdenii dokladov na publichnykh slushaniyakh 13 iyulya 2017 g. na publichnykh slushaniyakh pravoprimenitelnoy praktiki Upravleniya za II kvartal 2017 goda» (Upravleniye Rospotrebnadzora po g. Moskve, 2017) [“Answers to the questions of entrepreneurs received by the Department of Rospotrebnadzor in Moscow through the service for collecting questions (appeals), comments and comments on reports and when discussing reports at public hearings on July 13, 2017 at public hearings of law enforcement practice of Management for the second quarter of 2017" (Rospotrebnadzor In Moscow, 2017)]. URL: http:// www.consultant.ru/cons/cgi/online.cgi?req= doc\&base $=$ MLAW\&n=182763\#03934310176828566 (accessed 10 January 2021).

5. Postanovleniye Pravitelstva RF ot 19.01.1998 № 55 (red. ot 30.05.2018) «Ob utverzhdenii Pravil prodazhi otdelnykh vidov tovarov, perechnya tovarov dlitelnogo polzovaniya, na kotoryye ne rasprostranyayetsya trebovaniye pokupatelya o bezvozmezdnom predostavlenii emu na period remonta ili zameny analogichnogo tovara, i perechnya neprodovolstvennykh tovarov nadlezhashchego kachestva, ne podlezhashchikh vozvratu ili obmenu na analogichnyy tovar drugikh razmera, formy, gabarita, fasona, rastsvetki ili komplektatsii» [Resolution of the government of the Russian Federation of 19.01.1998 N 55 (ed. by 30.05.2018) “On approval of 
Rules of sale of separate kinds of goods, inventory of durable goods, are not subject to the requirement of the buyer about gratuitous granting to him for the period of repair or replacement of similar goods and list of nonfood goods of proper quality not subject to return or exchange for similar goods of other size, shape, size, style, color or configuration"]. Sobraniye zakonodatelstva $R F$ ["Collection of legislation of the Russian Federation"], 26.01.1998, no. 4, st. 482.

6. Postanovleniye Pravitelstva RF ot 10.11.2011 № 924 (red. ot 27.03.2019) «Ob utverzhdenii perechnya tekhnicheski slozhnykh tovarov» [Resolution of the Government of the Russian Federation of 10.11.2011 N 924 (ed. of 27.03.2019) "On approval of the list of technically complex goods"]. Sobraniye zakonodatelstva RF, 14.11.2011, no. 46, st. 6539.

7. Postanovleniye Pravitelstva RF ot 31.12.2020 № 2463 «Ob utverzhdenii Pravil prodazhi tovarov po dogovoru roznichnoy kupli-prodazhi. perechnya tovarov dlitelnogo polzovaniya, na kotoryye ne rasprostranyayetsya trebovaniye potrebitelya $o$ bezvozmezdnom predostavlenii emu tovara, obladayushchego etimi zhe osnovnymi potrebitelskimi svoystvami. na period remonta ili zameny takogo tovara, i perechnya neprodovolstvennykh tovarov nadlezhashchego kachestva, ne podlezhashchikh obmenu, a takzhe o vnesenii izmeneniy v nekotoryye akty Pravitelstva Rossiyskoy Federatsii» [Resolution of the Government of the Russian Federation of 31.12.2020 N 2463 "On approval of the Rules for the Sale of Goods under a retail purchase and Sale Agreement, the list of Durable goods that are not subject to the consumer's Demand for free provision of goods with the same Basic consumer properties for the Period of Repair or replacement of such Goods, and the list of Non-food goods of Proper quality that are not Subject to Exchange, as well as on amendments to Certain acts of the Government of the Russian Federation"]. URL: http://www. consultant.ru (accessed 12 January 2021).

8. Prokhorov A.Yu. Osobennosti realizatsii otdel'nykh prav potrebitelei pri obnaruzhenii nedostatkov priobretennykh avtotransportnykh sredstv [Features of the implementation of individual consumer rights when detecting shortcomings of purchased vehicles]. Nauka i obrazovanie: khozyaistvo i ekonomika; predprinimatel'stvo; pravo i upravlenie [Science and education: and Economics; entrepreneurship; law and management], 2015, no. 6(61), pp. 93-96.

9. Proekt Postanovleniya Pravitel'stva RF "O vnesenii izmenenii v Perechen' tekhnicheski slozhnykh tovarov» (po sostoyaniyu na 07.07.2016) (podgotovlen Minpromtorgom Rossii) (Postanovlenie podpisano 17.09.2016 № 929) [Draft Decree Of the government of the Russian Federation "On amendments to the List of technically complex goods" (as of 07.07.2016) (prepared by the Ministry of industry and trade of Russia) (Resolution signed on 17.09.2016 N 929)]. URL: http://www.consultant.ru (accessed 10 January 2021).

10. Proekt Postanovleniya Pravitel'stva RF "Ovnesenii izmeneniya v Perechen" tekhnicheskislozhnykhtovarov» (po sostoyaniyu na 05.10.2018) (podgotovlen Minpromtorgom Rossii) (Postanovlenie podpisano 27.03.2019 № 327) [Draft Decree of the Government of the Russian Federation "On making changes to the List of technically complex goods" (as of 05.10.2018) (prepared by the Ministry of industry and trade of Russia) (Resolution signed on 27.03.2019 N 327)]. URL: http://www.consultant.ru (accessed 10 January 2021).

11. Resheniye Kirovskogo rayonnogo suda g. Saratova № 2-4192/2018 2-4192/2018 M-4111/2018 M$4111 / 2018$ ot 24 iyulya 2018 g. po delu № 2-4192/2018 [Decision of the Kirovsky district court of Saratov no. 2-4192/2018 2-4192/2018 M-4111/2018 M-4111/ 2018 of July 24, 2018 in case no. 2-4192/2018]. Sudebnyye i normativnyye akty RF. URL: http:// sudact.ru/regular/doc/TuH5LbmBvMYw/ (accessed 10 January 2021).

12. Resheniye Moskovskogo rayonnogo suda g. Cheboksary (Chuvashskaya Respublika) № 2-3944/ 2016 ot 9 noyabrya 2016 g. po delu № 2-3944/2016 [Decision of the Moscow district court of Cheboksary (Chuvash Republic) No. 2-3944 / 2016 of November 9, 2016 in case No. 2-3944/2016]. Sudebnyye $i$ normativnyye akty RF. URL: http://sudact.ru/regular/ doc/hhclUTd0GPQX/ (accessed 10 January 2021).

13. Resheniye Nazarovskogo gorodskogo suda (Krasnoyarskiy kray) № 2-1463/2015 2-20/2016 2-20/ 2016(2-1463/2015;) M-997/2015 M-997/2015 ot 12 yanvarya 2016 g. po delu № 2-1463/2015 [Decision of the Nazarovsky city court (Krasnoyarsk territory) № 2-1463/2015 2-20/2016 2-20/2016(2-1463/2015;) M$997 / 2015$ M-997/2015 of January 12, 2016 in case No. 2-1463/2015]. Sudebnyye i normativnyye akty $R F$. URL: http://sudact.ru/regular/doc/bc0zUCB7ewYv/ (accessed 10 January 2021).

14. Resheniye Tsentralnogo rayonnogo suda g. Toliatti (Samarskaya oblast) № 2-3944/2018 2-3944/ 2018 M-3484/2018 M-3484/2018 ot 24 sentyabrya 2018 g. po delu № 2-3944/2018 [Decision of the Central district court of Tolyatti (Samara region) no. 2-3944/ 2018 2-3944/2018 M-3484/2018 M-3484/2018 of 24 September 2018 in case no. 2-3944/2018]. Sudebnyye i normativnyye akty RF. URL: http://sudact.ru/regular/ doc/IzV5cCS95bmX/ (accessed 10 January 2021)

15. Resheniye Promyshlennogo rayonnogo suda g. Stavropolya (Stavropolskiy kray) № 2-9082/2015 29082/2015 M-9319/2015 M-9319/2015 ot 17 dekabrya 2015 g. po delu № 2-9082/2015 [Decision of the Industrial district court of Stavropol (Stavropol 
territory) no. 2-9082/2015 2-9082/2015 M-9319/2015 M9319/2015 of December 17, 2015 in case no. 2-9082/ 2015]. Sudebnyye i normativnyye akty RF. URL: http:/ /sudact.ru/regular/doc/Ub0HCgVK4uxw/ (accessed 10 January 2021).
16. Shutikhina Z.A. Ponyatie, pravovaya priroda tekhnicheski slozhnogo tovara kak pravovoi kategorii [Concept, the legal nature of technically sophisticated products as a legal category]. Alleya nauki [Avenue of science], 2018, no. 7 (23), pp. 821-825.

\section{Information About the Authors}

Natalia A. Ablyatipova, Candidate of Sciences (Jurisprudence), Associate Professor, Honored Lawyer of the Republic of Kazakhstan, Department of Civil Law, Russian State University of Justice (Crimean Branch), Pavlenko St/Studencheskiy Lane, 5/2, 295006 Simferopol, Russian Federation, ve_na2014@mail.ru, mail@crb.rsuj.ru,https://orcid.org/0000-0002-4579-3871

Anastasia A. Kravtsova, Master Student, Russian State University of Justice (Crimean Branch), Pavlenko St/Studencheskiy Lane, 5/2, 295006 Simferopol, Russian Federation, nastia.kravtsova@gmail.com, mail@crb.rsuj.ru, https://orcid.org/0000-0001-9754-0836

\section{Информация об авторах}

Наталья Айдеровна Аблятипова, кандидат юридических наук, доцент, заслуженный юрист Республики Казахстан, доцент кафедры гражданского права, Российский государственный университет правосудия (Крымский филиал), ул. Павленко/переулок Студенческий, 5/2, 295006 г. Симферополь, Российская Федерация, ve na2014@mail.ru, mail@crb.rsuj.ru, https://orcid.org/0000-0002-4579-3871

Анастасия Алексеевна Кравцова, магистрант, Российский государственный университет правосудия (Крымский филиал), ул. Павленко/переулок Студенческий, 5/2, 295006 г. Симферополь, Российская Федерация, nastia.kravtsova@gmail.com, mail@crb.rsuj.ru, https://orcid.org/0000-0001-9754-0836 